\title{
Follicular and hormonal development in prepubertal heifers from 2 to 36 weeks of age
}

\author{
A. C. O. Evans ${ }^{1 *}$, G. P. Adams ${ }^{2}$ and N. C. Rawlings ${ }^{1+}$ \\ ${ }^{1}$ Department of Veterinary Physiological Sciences and ${ }^{2}$ Department of Veterinary Anatomy, \\ Western College of Veterinary Medicine, University of Saskatchewan, Saskatoon, Saskatchewan, \\ S7N oWo, Canada
}

\begin{abstract}
The aim of this study was to characterize changes in ovarian follicle dynamics in relation to changes in hormone secretion in heifer calves from birth to 8 months of age. The position and diameter of ovarian follicles $\geq 4 \mathrm{~mm}$ in diameter were recorded, the number of ovarian follicles $\geq 2 \mathrm{~mm}$ in diameter counted, and blood samples collected daily for periods of 18 days, starting at 2, 8, 14, 24 and 34 weeks of age in ten heifers. The mean age at first ovulation was $52.8 \pm 1.6$ weeks. At all ages ovarian follicular development occurred in a wave-like manner, as in mature cattle. The maximum diameter of the dominant and the largest subordinate follicles increased between 2 and 34 weeks of age $(P<0.05)$; however, the greatest increase occurred between 2 and 8 weeks of age. There was a similar increase in the numbers of small and large ovarian follicles $(P<0.05)$. The duration of detection of dominant follicles (number of days visible at a diameter of $\geq 4 \mathrm{~mm}$ ) also increased between 2 and 34 weeks of age $(P<0.05)$. The emergence of waves of follicular development was preceded by peaks in plasma FSH concentrations $(P<0.05)$ at 2 weeks of age but this was less clear at other ages. There was a rise in circulating concentrations of gonadotrophins between 4 and 14 weeks of age. We concluded that in heifer calves as young as 2 weeks of age ovarian follicles grew in a wave-like fashion, similar to those of adult cattle. We speculate that the early rise in gonadotrophin secretion stimulated the increase in numbers of follicles and follicle diameters observed, indicating an early critical step in reproductive development.
\end{abstract}

\section{Introduction}

Transrectal ultrasonography was used to show that follicular growth in adult cows occurs in waves (Pierson and Ginther, 1988; Savio et al, 1988; Sirois and Fortune, 1988); a group of antral follicles emerge synchronously and one dominant follicle grows to a diameter greater than that of the other (subordinate) follicles (Adams et al., 1992). In cattle, most oestrous cycles comprise two or three waves of follicular development, with the dominant follicle of the last wave ovulating (Ginther et al., 1989b).

In some studies, wave-like patterns of follicular growth have not been demonstrated in prepubertal heifers, where follicular wave definitions were based on describing changes in numbers of follicles between different days (Rajakoski, 1960; Ginther et al., 1989a; Knopf et al., 1989). In other studies, a well-ordered wave pattern of follicular development has been documented in prepubertal heifers as young as 8 months of age (Adams et al., 1994), but few changes in follicle dynamics were apparent from 8 months of age to first ovulation (Evans et al, 1994).

*Present address: Department of Physiology, College of Veterinary Medicine, Corneli University, Ithaca, NY 14853, USA.

tCorrespondence.

Received 30 June 1994
In studies with slaughtered heifer calves (Erickson, 1966; Desjardins and Hafs, 1969) there was an increase in the total number of antral follicles from birth until 4-6 months of age. Thereafter, it was suggested that there was either a decrease in the numbers of ovarian follicles until 12 months of age (Desjardins and Hafs, 1969), or that the population of follicles remained constant well into maturity (Erickson, 1966).

Some studies in heifer calves have shown that serum concentrations of LH and FSH were low during the first month after birth, increased to a peak value at 3-4 months of age, and then decreased to 6 months of age (Schams et al., 1981; Evans et al., 1992). However, others have noted that serum LH and FSH concentrations decreased from birth to about 15 weeks of age and then increased to 39 weeks of age (Dodson et al., 1988). It has been suggested that an early rise in gonadotrophin secretion, before 6 months of age in heifer calves, may be a critical early step in postnatal sexual development (Evans et al., 1992) and that this may stimulate an increase in the number of ovarian follicles, as described in studies with slaughtered animals (Desjardins and Hafs, 1969; Erickson, 1966).

No systematic ultrasonographic study of ovarian follicular dynamics has been done in young heifer calves from birth to 8 months of age, and patterns of gonadotrophin secretion are 
unclear. The objective of the present study was to use periods of daily transrectal ovarian ultrasonography to describe the pattern of ovarian follicular growth from birth to 8 months of age. We also attempted to clarify the patterns of gonadotrophin secretion over this period and relate them to changes in ovarian follicular dynamics.

\section{Materials and Methods}

\section{Animals}

Ten age-matched (born 30 March \pm 3 days) Hereford heifer calves were weighed every 4 weeks and were suckled at pasture until weaning at 26 weeks of age. From 26 weeks of age they were kept in a corral and provided, ad libitum, with brome-alfalfa hay, water and a ground concentrate ration (by mass, $21 \%$ barley, $51 \%$ hay, $22 \%$ straw and $0.005 \%$ of a $1: 1$ calcium phosphorus mineral mix).

\section{Examinations and blood collection}

Daily ultrasound examinations were conducted for periods of 18 days starting at 2,8,14,24 and 34 weeks of age. The observation periods were expected to encompass the emergence of two consecutive waves of follicular development (Adams ef al., 1994). During each period of observation, the ovaries of each heifer were examined by transrectal ultrasonography using a B-mode scanner and a $7.5 \mathrm{MHz}$ linear-array transducer (Aloka SSD-500, Overseas Monitor Corporation Ltd, Richmond, BC). At 2 and 8 weeks of age a rigid transducer $(30 \mathrm{~cm} \times 1.6 \mathrm{~cm})$, designed for transrectal prostate examination in humans, was used and manipulated externally to allow imaging of the reproductive tract. At 14 and 24 weeks of age, a longer rigid transducer was needed; a $40 \mathrm{~cm}$ length of polyethylene tubing ( $15 \mathrm{~mm}$ o.d., $12 \mathrm{~mm}$ i.d.), cut along its length, and a $38 \mathrm{~cm}$ brass rod ( $5 \mathrm{~mm}$ diameter) were therefore taped around the cord of a standard I-shaped $7.5 \mathrm{MHz}$ linear-array transducer, usually used for transrectal examinations in adult animals. At 34 weeks of age, the heifers were large enough to allow ultrasound examinations by intrarectal placement of a gloved hand holding the transducer. Each day the position and diameter of individually identified follicles $\geq 4 \mathrm{~mm}$ in diameter were recorded on a diagram, and the number of follicles $\geq 2 \mathrm{~mm}$ in diameter were counted, as described for late prepubertal heifers by Adams et al. (1994) and for sexually mature heifers by Knopf et al. (1989).

On each day of ultrasound examination, a single blood sample was collected by jugular venepuncture and plasma was harvested. A single blood sample was collected every week from 2 to 26 weeks of age and then every 2 weeks until 36 weeks of age, and serum was harvested. The age at first ovulation (puberty) was defined as the age at which plasma progesterone concentrations first exceeded $3.2 \mathrm{nmol} \mathrm{l}^{-1}$ in plasma samples collected every 3 or 4 days (twice a week) between 46 and 60 weeks of age. In a previous study, the first ovulation of similar heifers occurred at 56 weeks of age (Evans et al., 1992). A heifer was described as having a luteal phase of short duration if the first one or two consecutive increases in progesterone concentrations (of plasma $>3.2 \mathrm{nmol} \mathrm{1}^{-1}$ ) were followed by a concentration $<1.6 \mathrm{nmol}^{-1}$. Blood samples were collected from five of the heifers every $15 \mathrm{~min}$ for $12 \mathrm{~h}$ (4 ml, 08:00 h to 20:00 h) at 5, 10, 15, 25 and 35 weeks of age, to assess the pulsatile nature of circulating serum LH and FSH concentrations. Ultrasound examinations were conducted during the $12 \mathrm{~h}$ intensive bleeding periods (between 09:00 $\mathrm{h}$ and 11:00 h), and the calves were housed loose with their cows haltered; water and hay were freely available. One day before intensive blood sampling, indwelling jugular catheters (vinyl tubing, $1.0 \mathrm{~mm}$ i.d., $1.5 \mathrm{~mm}$ o.d.; Dural Tubing: Critchley Electrical Products, Dural, NSW) were inserted. For the collection of serum, blood samples were allowed to clot for 18-24 h, the samples were centrifuged for $15 \mathrm{~min}$ at $1500 \mathrm{~g}$ at room temperature, and the serum harvested. For the collection of plasma, blood samples were collected into $10 \mathrm{ml}$ heparinized vacutainers (Becton Dickinson \& Co., Rutherford, NJ) and centrifuged within $30 \mathrm{~min}$ of collection. All samples were stored at $-20^{\circ} \mathrm{C}$ until analysis.

\section{Radioimmunoassays}

All samples were analysed, in duplicate, for concentrations of LH and FSH by validated radioimmunoassay (Rawlings et al., 1984; Evans et al., 1992). LH concentrations are expressed in terms of NIDDK-bLH4, and the range of the standard curve was from 0.06 to $8 \mathrm{ng} \mathrm{ml}^{-1}$. The sensitivity of the LH assay was $0.1 \mathrm{ng} \mathrm{ml} \mathrm{ml}^{-1}$ (defined as the lowest concentration of unlabelled LH capable of displacing iodinated LH from the first antibody, $P<0.05$ ). The intra- and interassay coefficients of variation (CVs) were $10 \%$ and $13 \%$, or $6 \%$ and $11 \%$ for reference sera, with mean $\mathrm{LH}$ concentrations of $0.29 \mathrm{ng} \mathrm{ml}^{-1}$ or $0.82 \mathrm{ng} \mathrm{ml}^{-1}$, respectively. Reference sera were replicated in every assay. The first antibody used in the FSH assays was NIDDK-anti-oFSH-1, and concentrations are expressed in terms of USDA-bFSH-II. The range of the standard curve was from 0.13 to $16 \mathrm{ng} \mathrm{ml}^{-1}$ and the assay sensitivity was $0.2 \mathrm{ng} \mathrm{ml}^{-1}$. The intra- and interassay CVs were $6 \%$ and $12 \%$, or $7 \%$ and $13 \%$ for reference sera, with mean FSH concentrations of $1.31 \mathrm{ng} \mathrm{ml}^{-1}$ or $2.45 \mathrm{ng} \mathrm{ml}^{-1}$, respectively.

Progesterone concentrations were measured, in duplicate, by validated radioimmunoassay (Rawlings et al., 1984; Evans et al., 1992), in samples collected each day during the 18 day ultrasound period that started at 35 weeks of age, and in those samples collected twice per week from 46 weeks of age until puberty. The sensitivity of the assay was $0.3 \mathrm{nmol}^{-1}$ and the standard curve ranged from 0.3 to $31.8 \mathrm{nmol} \mathrm{l}^{-1}$. The intraand interassay CVs were $7 \%$ and $11 \%$, or $7 \%$ and $17 \%$ for reference sera, with mean progesterone concentrations of $2.16 \mathrm{nmol} \mathrm{I}^{-1}$ or $11.51 \mathrm{nmol} 1^{-1}$, respectively.

Oestradiol was measured, in duplicate, by validated radioimmunoassay (Joseph et al., 1992; Evans et al., 1992) in samples from each of the five periods of ultrasound examination. Pooled samples from two consecutive days, corresponding to the end of the growth phase of each dominant follicle were assayed. All samples were analysed in one assay in which the range of the standard curve was $3.7-183.6 \mathrm{pmol} \mathrm{l}^{-1}$ and the assay sensitivity was $3.7 \mathrm{pmol} \mathrm{I}^{-1}$. The intra-assay $\mathrm{CV}$ was $17 \%$, or $16 \%$ for reference sera, with mean oestradiol concentrations of $15.1 \mathrm{pmol} \mathrm{l}^{-1}$ or $36.3 \mathrm{pmol} \mathrm{l}^{-1}$, respectively. 

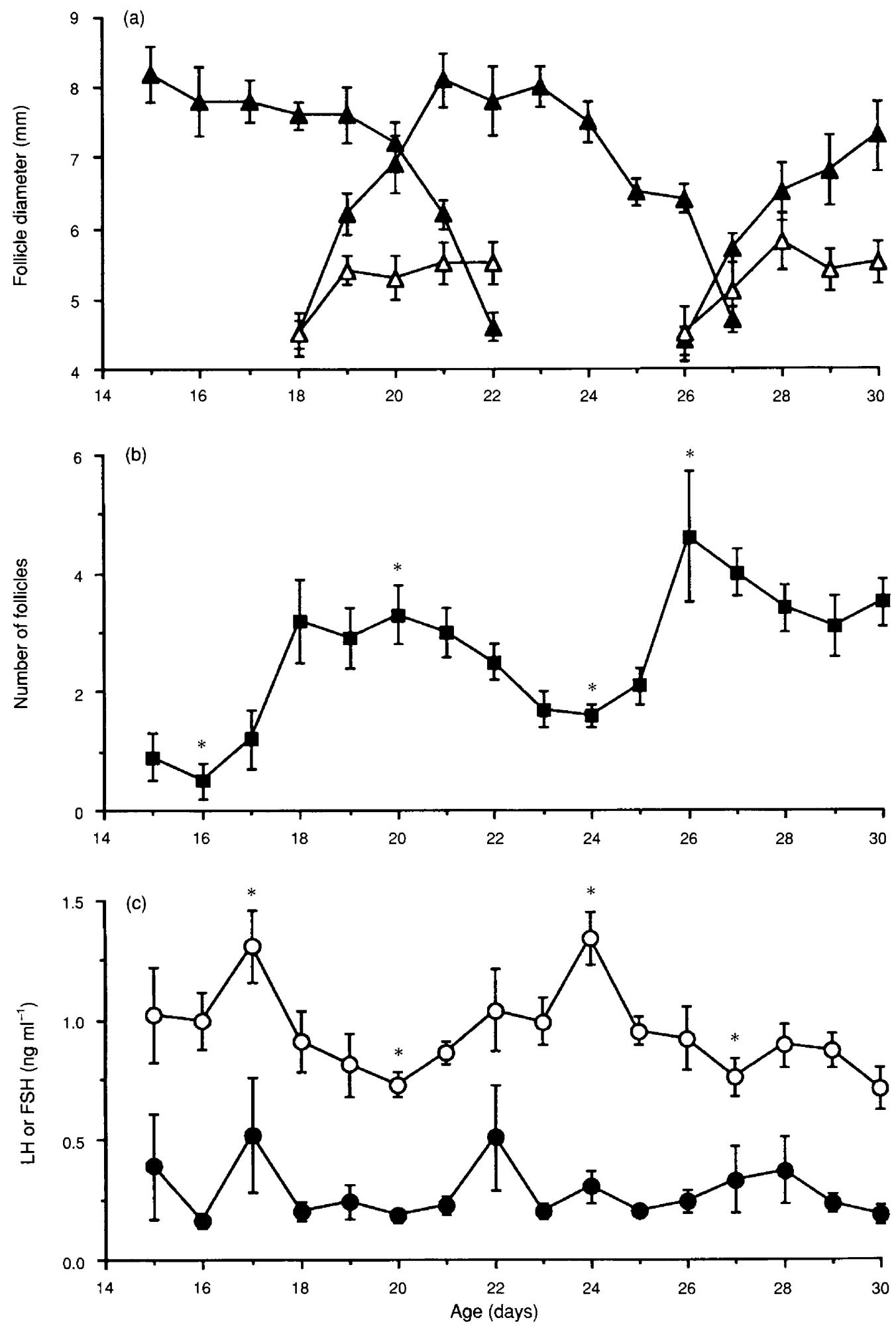

Fig. 1. (a) Follicle diameters (dominant $\boldsymbol{\Delta}$, largest subordinate $\Delta$ ), (b) numbers of follicles $\geq 4 \mathrm{~mm}$ in diameter and (c) associated serum gonadotrophin concentrations ( $\mathrm{FSH} O, \mathrm{LH}$ ) based on daily ultrasound examination and blood sampling, starting at 2 weeks of age in heifers (mean \pm SEM; $n=10$ ). Values are plotted to the mean day of age. *Peak values differ from nadir values $(P<0.05)$. 

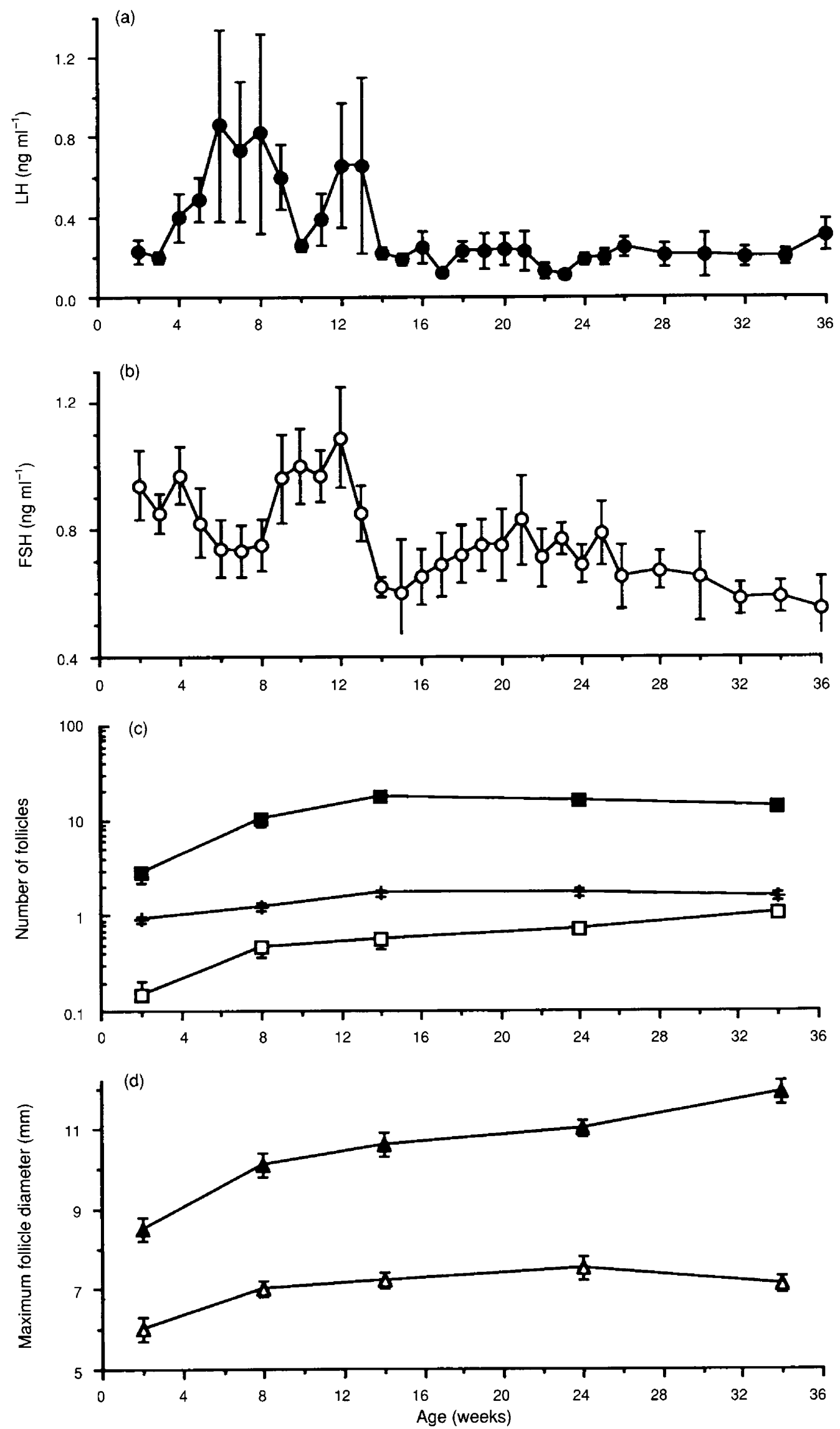


\section{Analysis of data}

To determine whether follicular development occurred in waves, daily changes in the total number of follicles $\geq 4 \mathrm{~mm}$ in diameter were assessed in relation to the growth and regression of the largest follicle, as described by Ginther et al. (1989a) and Adams et al. (1994). Total numbers of follicles were aligned to the mean day of emergence of successive large antral follicles and included 3 days before the day of emergence. Periodic increases $(P<0.05)$ in the numbers of follicles, in association with the growth of a large follicle, followed by a decrease $(P<0.05)$ in numbers of follicles, during the period of maximum diameter of the largest follicle, were taken as a wave-like pattern of follicular development. If a wave-like pattern was observed, the largest follicle of a wave was defined as the dominant follicle and the follicles emerging at the same time, but attaining a smaller diameter, were defined as subordinate follicles (Ginther et al, 1989a). Daily plasma concentrations of LH and FSH were normalized with the follicle data to the days of emergence of successive dominant follicles (Adams et al., 1992; Adams et al., 1994).

Those growth profiles of dominant follicles that were seen in their entirety at each age were divided into growing, static and regressing phases (Ginther et al., 1989a). The growing phase extended from the day of emergence (day before it first exceeded $4 \mathrm{~mm}$ in diameter) to the day that it appeared to stop its progressive increase in diameter. The regressing phase was defined as the period from when the follicle was first observed to decrease in diameter until it was first detected at $4 \mathrm{~mm}$ in diameter. The static phase was defined as the period between the end of the growing phase and the beginning of the regressing phase (Ginther et al., 1989a). The duration of detection of dominant follicles was defined as the number of days that a dominant follicle was seen in the ovary from the beginning of the growing phase (at $4 \mathrm{~mm}$ in diameter) to the end of the regressing phase (at $4 \mathrm{~mm}$ in diameter). Interwave intervals were defined as the number of days between the emergence of successive dominant follicles. Follicles were also classified into three size ranges, small $(3-5 \mathrm{~mm}$ diameter), medium $(6-8 \mathrm{~mm}$ diameter) and large $(9 \mathrm{~mm}$ diameter and larger) follicles. The ratio of the diameter of the largest subordinate to the dominant follicle was also calculated.

The characteristics of the pulsatile secretion of LH and FSH were determined using PC-Pulsar (J. Gitzen and V. Ramirez, University of Illinois, USA). Standard deviation criteria of height ( $G$ values) and duration were used for pulse detection (Merriam and Wachter, 1982).

\section{Statistical analyses}

All data were analysed for the effect of time using multivariate and univariate repeated measures analysis of variance (SAS Version 6.07, SAS Institute Inc., Cary, NC), with degrees of freedom set by the Greenhouse, Geyser, Epsilon adjustment. If main effects were significant, multiple comparisons were made using the method of Tukey (Honestly Significant Difference) for post-ANOVA multiple comparisons $(P<0.05)$. All data are presented as means \pm SEM and the probability in parentheses represents the main effects in the analysis of variance.

\section{Results}

On the basis of plasma progesterone concentrations ( $>3.2 \mathrm{nmol} \mathrm{l}^{-1}$ ), the mean age at puberty was $52.8 \pm 1.6$ weeks of age at a bodymass of $386.7 \pm 12.7 \mathrm{~kg}$. The mean gain in mass from birth to puberty was $6.7 \pm 0.3 \mathrm{~kg}$ per week. All the heifers had an initial apparent short luteal phase of 7 days or less.

\section{Ovarian follicles}

At all ages there were periodic $(P<0.05)$ increases in the total numbers of ovarian follicles $\geq 4 \mathrm{~mm}$ in diameter, temporally associated with the growth of large ovarian follicles ( 2 week old data; Fig. 1). No ovulations or corpora lutea were observed during any period of ultrasound examination. There was an increase with age in the mean number of small, medium and large follicles $(P<0.001$; Fig. 2). The number of both small and medium sized follicles increased from 2 to 14 weeks of age (2.8 $\pm 0.5-17.7 \pm 2.0$ follicles and $0.9 \pm 0.1-1.7 \pm 0.1$ follicles, respectively), but did not change thereafter until 34 weeks of age (17.7 $\pm 2.0-13.6 \pm 1.9$ follicles and $1.7 \pm 0.1-1.6 \pm 0.2$ follicles, respectively; Fig. 2). Numbers of large ovarian follicles increased from 2 to 34 weeks of age $(0.2 \pm 0.1-1.1 \pm 0.1$ follicles; Fig. 2). The maximum diameter of the dominant follicles increased between 2 and 34 weeks of age (8.5 $\pm 0.3-$ $11.9 \pm 0.3 \mathrm{~mm}, P<0.0001$ ); however, the maximum diameter of the largest subordinate follicles increased from 2 to 14 weeks of age $(6.0 \pm 0.3-7.0 \pm 0.2 \mathrm{~mm})$ and remained constant thereafter $(7.1 \pm 0.2 \mathrm{~mm}$ at 34 weeks; Fig. 2). The ratio of the diameters of the largest subordinate to that of the dominant follicles showed a tendency to decrease with age but the effect was not significant $(P=0.07 ; 71 \pm 3 \%$ at 2 weeks old and $61 \pm 3 \%$ at 34 weeks old).

There was no change in the duration of the growth phase $(P=0.08)$, the static phase $(P=0.13)$ or the regression phase $(P=0.79$, Table 1$)$ of the dominant follicle among ages; however, the time when the dominant follicle could be detected did increase from 2 to 34 weeks of age $(P<0.05$, Table 1). As the heifers matured, there was no change in the growth rate $\left(1.4 \pm 0.2 \mathrm{~mm}\right.$ day $\left.^{-1}\right)$ or regression rate $\left(1.2 \pm 0.1 \mathrm{~mm} \mathrm{day}^{-1}\right)$ of the dominant follicles $(P>0.05)$. The interwave interval showed a significant main effect of time

Fig. 2. Mean ( $\pm \operatorname{SEM}, n=10$ ) serum concentrations of (a) LH and (b) FSH in heifers bled weekly from 2 to 26 weeks of age and every 2 weeks from 26 to 36 weeks of age. (c) Numbers of small ( $\square, 3-5 \mathrm{~mm}$ in diameter), medium $(\mp, 6-8 \mathrm{~mm}$ in diameter) and large follicles $(\square, \geq 9 \mathrm{~mm}$ in diameter; $P<0.001$ in each category) and (d) the maximum diameter of the dominant $(\boldsymbol{\Delta}, P<0.0001)$ and largest subordinate follicles $(\triangle$, $P<0.004)$ in heifers at $2,8,14,24$ and 34 weeks of age, as determined by transrectal ultrasonography. Numbers of small and medium sized follicles increased from 2 to 14 weeks of age $(P<0.05)$. Numbers of large follicles and the maximum diameter of dominant follicles increased from 2 to 34 weeks of age $(P<0.05)$. The maximum diameter of the largest subordinate follicle increased from 2 to 14 weeks of age $(P<0.05)$. 
Table 1. Mean ( \pm SEM) characteristics of the dominant follicle of follicular waves in prepubertal heifers $(n=10)$ between 2 and 34 weeks of age, as determined by daily transrectal ultrasonography

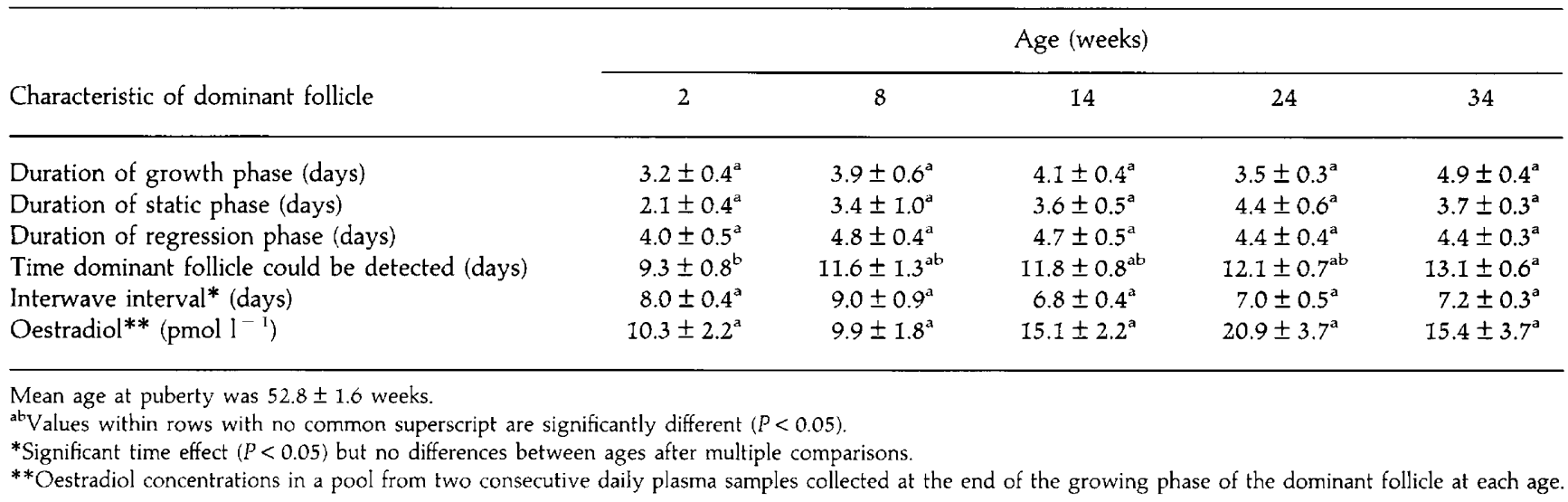

$(P<0.05)$; however, Tukey's multiple comparisons did not reveal differences between ages (Table 1 ).

\section{Hormone concentrations}

Oestradiol concentrations in serum, associated with the end of the growing phase of the dominant follicles, tended $(P<0.09)$ to increase with age (Table 1$)$. Some increase in serum concentrations of FSH was apparent before the emergence of waves of follicles in this study; however, significant peaks were seen only in 2-week-old heifers $(P<0.01$; Fig. 1$)$. No significant changes in $\mathrm{LH}$ concentrations in serum were detected in association with follicular waves at any age $(P>0.50 ; 2$ week data Fig. 1). Similarly, no changes in plasma progesterone concentrations were detected in association with waves of follicular development at 34 weeks of age (mean $0.29 \pm 0.13 \mathrm{nmol} \mathrm{l}^{-1}, P>0.70$ ).

On the basis of serum samples collected weekly and every 2 weeks of age, concentrations of FSH changed significantly with time $(P<0.02)$, but LH concentrations did not $(P<0.2)$. However, when the values were blocked into four week intervals, concentrations of FSH at 10-13 weeks of age were greater than those between 14-17 and 22-36 weeks of age $(P<0.001)$, and LH concentrations at $6-9$ weeks of age were greater than those between $2-5$ and $14-32$ weeks of age $(P<0.001)$.

Mean and basal FSH concentrations were greater at 5 and 10 weeks of age than at 15 and 35 weeks of age $(P<0.05)$ (Fig. 3). There was a significant effect of time $(P<0.05)$ on both LH pulse frequency and basal LH secretion; however, multiple comparisons between means did not show differences between ages (Fig. 3).

\section{Discussion}

The wave-like pattern of follicular development seen in our heifers at all ages was similar to that seen in adult cattle (Savio et al., 1988; Knopf et al., 1989) and late prepubertal heifers (Adams et al., 1994; Evans et al., 1994). The growth and regression rates of dominant follicles were comparable to late prepubertal heifers (Adams et al., 1994) and to cyclic cows (Sirois and Fortune, 1988; Ginther et al., 1989a), as was the pattern of follicular dominance (Ginther et al., 1989a; Adams et al., 1993). In the heifers in our study, FSH concentrations in serum appeared to increase before the emergence of waves of follicular development; however, significant changes in FSH secretion were seen only in 2-week-old heifers. In adult cows (Adams et al., 1992; Adams et al., 1993) and late prepubertal heifers (Adams et al., 1994; Evans et al., 1994), serum concentrations of FSH reach a peak before the emergence of waves of follicular growth.

Despite the increase seen in the maximum diameter of the dominant and largest subordinate follicles, as the heifers grew, there was a tendency for a decrease in the ratio between the diameter of the largest subordinate and dominant follicles between 2 and 34 weeks of age. This may reflect an increase in the strength of dominance of the dominant follicle over subordinate follicles as the heifers became older. Between 2 and 34 weeks of age, there were no significant changes in the duration of either follicle growth, or the static or regression phases of the dominant follicles. There was an increase in the duration of detection of the dominant follicles with age $(P<0.05$, Table 1$)$; this probably reflected the additive effects of small and non-significant increases in the duration of the growing, static and regression phases with age. Hence, as the heifers matured, ovarian follicles grew and persisted on the ovary for longer.

Desjardins and Hafs (1969) observed an increase in the number of large and small ovarian follicles ( $>5$ and $<5 \mathrm{~mm}$ diameter) from birth to 4 months of age. A similar pattern was seen in the present study. The marked increase seen in the number of small ovarian follicles from birth to 3 or 4 months of age in our study paralleled an increase in superovulatory response seen in calves by Seidel et al. (1971) and Armstrong et al. (1992). The marked increase in follicular growth over the course of this study in young heifers represents the major phase of postnatal follicular development. In a separate study of heifers from 8 months of age to first ovulation (Evans et al., 1994), only minor changes in numbers of follicles and 

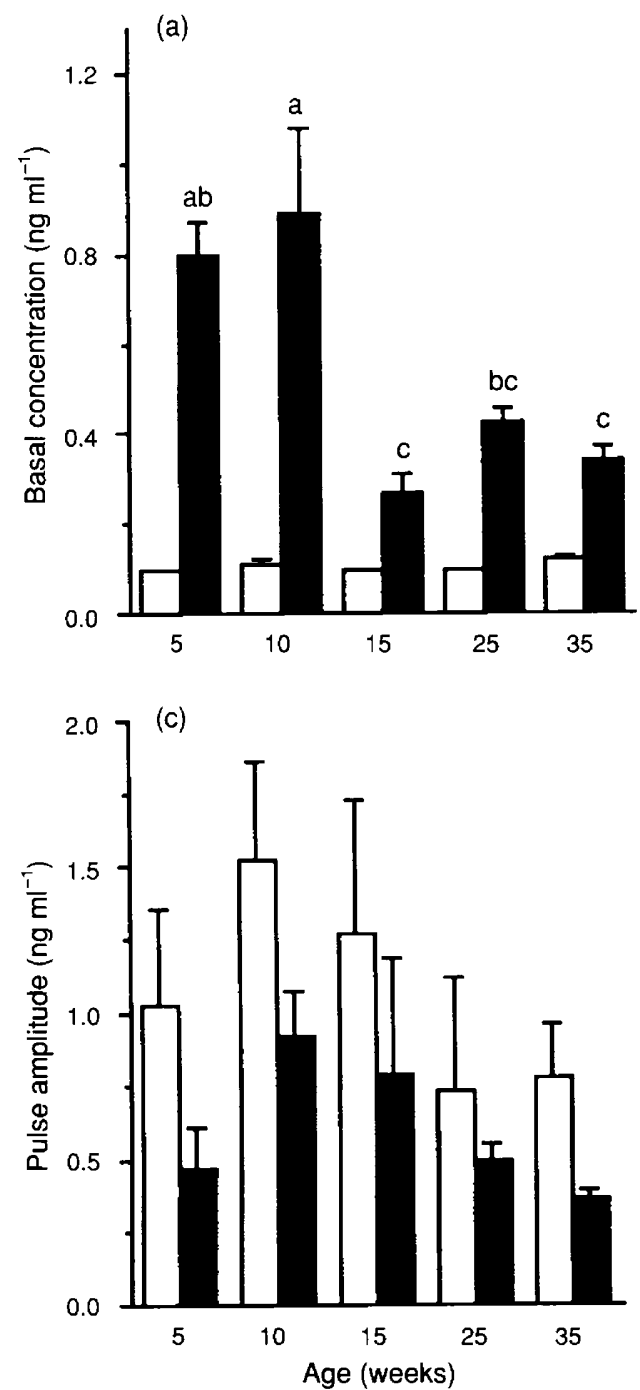
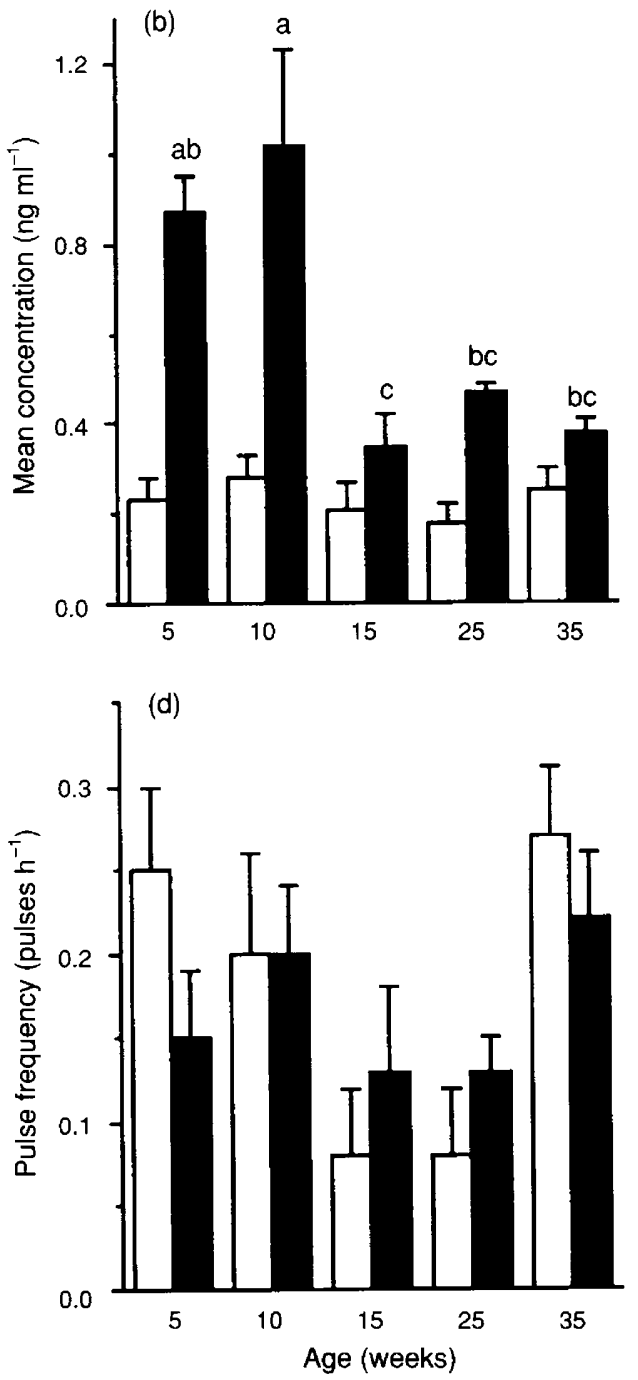

Fig. 3. (a) Basal and (b) mean serum concentrations, (c) pulse amplitude and (d) frequency of LH ( $\square$ ) and FSH $(\boldsymbol{G})$ in heifers $(n=5)$ bled every $15 \mathrm{~min}$ for $12 \mathrm{~h}$ at $5,10,15,25$ and 35 weeks of age. Significant differences between ages for each hormone are shown by different letters $(P<0.05)$. There was a significant effect of time $(P<0.05)$ for basal LH concentrations and LH pulse frequency; however, multiple comparisons did not show differences between ages.

maximum follicle size were seen among follicular waves as heifers approached first ovulation.

The endocrine data in this study support previous findings that there is an early rise in gonadotrophin secretion between 2 and 5 months of age in prepubertal heifers (Schams et al., 1981; Evans et al., 1992). On the basis of a previous study, we expected the early rise in gonadotrophin secretion to be due to an increase in pulse amplitude (Evans et al., 1992); however, the apparent changes in $\mathrm{LH}$ pulse amplitude with age did not reach significance in the present study. A physiological role for the early rise in gonadotrophin secretion has not yet been ascribed. A similar increase has been reported in the developing bull calf (Rawlings et al., 1978; McCarthy ef al., 1979; Evans et al., 1993) and it has been suggested that it may aid normal testicular growth and development (McCarthy et al., 1979; Amann and Walker, 1983). In the present study, the most marked increases in maximum follicle diameter and total numbers of follicles were between 2 and 14 weeks of age, coincident with the time that gonadotrophin secretion was high. Similar increases in numbers of follicles in ovaries collected at slaughter (Erickson, 1966; Desjardins and Hafs, 1969) and after ovariectomy (Dodson et al., 1989) have been observed. We speculate that increased gonadotrophin secretion in young prepubertal calves stimulates an increase in follicular activity, and may aid the enhancement of the organized ovarian cyclicity that persists throughout reproductive life. Cohen et al. (1987) found that the treatment of calves from birth with steroid-releasing implants reduced pregnancy rates once the animals were mature; however, treatment from six months of age had no effect. The steroid-releasing implants may have decreased gonadotrophin secretion during a critical early period of development and led to improper maturation of the reproductive system, 
highlighting the importance of a correct endocrine balance in young prepubertal heifers.

The regulation of the early rise in gonadotrophin secretion is unclear. The cessation of the early rise may be due to the establishment or enhancement of negative feedback regulation of gonadotrophin secretion by ovarian products (oestradiol and inhibin). These could have been produced in increasing amounts by enhanced gonadotrophin stimulation of large ovarian follicles. This hypothesis is consistent with ovariectomy experiments, where it was concluded that an ovarian inhibitory mechanism, controlling gonadotrophin secretion, develops between 2 and 12 weeks of age (Dodson et al., 1989). Both follicular fluid oestradiol concentrations (Dodson et al., 1989) and plasma oestradiol concentrations (present study) showed a tendency to increase with age. Between 2 and 8 weeks of age it was shown that there was an increase in the functional capacity of granulosa cell membranes (in terms of an increase in in vitro adenylate cyclase activity) in response to gonadotrophin stimulation (Wandji et al., 1992). Hence, about the time of the early rise in gonadotrophin secretion, there appears to be a qualitative change in ovarian follicular function as well as an increase in the number and diameter of antral follicles.

In conclusion, ovarian antral follicles develop in a wave-like fashion in calves as early as 2 weeks of age; this pattern resembles that seen in adult cattle. Waves of follicular development appeared to be preceded by peaks in serum FSH concentrations, but these were only significant at 2 weeks of age. Serum concentrations of $\mathrm{LH}$ and FSH were high between 2 and 14 weeks of age, when numbers of ovarian follicles and maximum diameters of follicles increased. We suggest that the early rise in gonadotrophin secretion plays an important role in stimulating ovarian follicle growth in heifers, and follicular products may be involved in terminating the early rise in gonadotrophin secretion. The time of the early rise in gonadotrophin secretion may reflect a critical developmental stage in the reproductive maturation of heifer calves.

The authors thank S. Cook for technical assistance, W. Kerr and his staff for care and management of the animals, USDA for the provision of purified bFSH and NIDDK for the provision of anti-oFSH and purified bLH. This research was supported by the Natural Sciences and Engineering Research Council of Canada. A. C. O. Evans was supported by a scholarship from the College of Graduate Studies and Research, University of Saskatchewan.

\section{References}

Adams GP, Matteri RL, Kastelic JP, Ko JCH and Ginther OJ (1992) Association between surges of follicle-stimulating hormone and the emergence of follicular waves in heifers Journal of Reproduction and Fertility 94 177-188

Adams GP, Kot K, Smith CA and Ginther OJ (1993) Selection of a dominant follicle and suppression of follicular growth in heifers Animal Reproduction Science 30 259-271

Adams GP, Evans ACO and Rawlings NC (1994) Follicular waves and circulating gonadotrophins in 8-month-old prepubertal heifers Journal of Reproduction and Fertility 100 27-33

Amann RP and Walker OA (1983) Changes in the pituitary-gonadal axis associated with puberty in Holstein bulls Journal of Animal Science $\mathbf{5 7}$ $433-442$
Armstrong DT, Holm P, Irvine B, Petersen BA, Stubbings RB, McLean D, Stevens G and Seamark RF (1992) Pregnancies and live birth from in vitro fertilization of calf oocytes collected by laparoscopic follicular aspiration Theriogenology $38 \quad 667-678$

Cohen RDH, Janzen ED and Nicholson HH (1987) Effect of repeated implantation with zeranol from birth or weaning on growth and reproduction in beef heifers Canadian Journal of Animal Science 67 37-42

Desjardins C and Hafs HD (1969) Maturation of bovine female genitalia from birth through puberty journal of Animal Science 28 502-507

Dodson SE, McLeod BJ, Haresign W, Peters AR and Lamming GE (1988) Endocrine changes from birth to puberty in the heifer Journal of Reproduction and Fertility 82 527-538

Dodson SE, Haresign W and Peters AR (1989) Ovarian control of gonadotrophin secretion in prepubertal heifers Animal Reproduction Science 21 1-10

Erickson BH (1966) Development and senescence of the postnatal bovine ovary Journal of Animal Science 25 800-805

Evans ACO, Currie WD and Rawlings NC (1992) Effects of naloxone on circulating gonadotrophin concentrations in prepubertal heifers Journal of Reproduction and Fertility 96 847-855

Evans ACO, Currie WD and Rawlings NC (1993) Opioidergic regulation of gonadotrophin secretion in the early prepubertal bull calf Journal of Reproduction and Fertility 99 45-51

Evans ACO, Adams GP and Rawlings NC (1994) Endocrine and ovarian follicular changes leading up to first ovulation in prepubertal heifers Journal of Reproduction and Fertility 100 187-194

Ginther OJ, Kastelic JP and Knopf L (1989a) Composition and characteristics of follicular waves during the bovine estrous cycle Animal Reproduction Science $20187-200$

Ginther OJ, Knopf L and Kastelic JP (1989b) Temporal associations among ovarian events in cattle during oestrous cycles with two and three follicular waves Journal of Reproduction and Fertility 87 223-230

Joseph IBJK, Currie WD and Rawlings NC (1992) Effects of time after ovariectomy, season, and oestradiol on luteinizing hormone and follicle-stimulating hormone secretion in ovariectomized ewes Journal of Reproduction and Fertility 94 511-523

Knopf L, Kastelic JP, Schallenberger E and Ginther OJ (1989) Ovarian follicular dynamics in heifers: test of two-wave hypothesis by ultrasonically monitoring individual follicles Domestic Animal Endocrinology 6 111-120

McCarthy MS, Hafs HD and Convey EM (1979) Serum hormone patterns associated with growth and sexual development in bulls Journal of Animal Science 49 1012-1020

Merriam GR and Wachter KW (1982) Algorithms for the study of episodic hormone secretion American Journal of Physiology 243 E310-E318

Pierson RA and Ginther OJ (1988) Ultrasonic imaging of the ovaries and uterus in cattle Theriogenology $2921-38$

Rajakoski E (1960) The ovarian follicular system in sexually mature heifers with special reference to seasonally, cyclical, and left-right variations Acta Endocrinologica Supplementum 52 1-68

Rawlings NC, Fletcher PW, Henricks DM and Hill JR (1978) Plasma luteinizing hormone ( $\mathrm{LH}$ ) and testosterone levels during sexual maturation in beef bull calves Biology of Reproduction 19 1108-1112

Rawlings NC, Jeffcoate IA and Rieger DL (1984) The influence of estradiol-17 $\beta$ and progesterone on peripheral serum concentrations of luteinizing hormone and follicle stimulating hormone in the ovariectomized ewe Theriogenology $22473-488$

Savio JD, Keenan L, Boland MP and Roche JF (1988) Pattern of growth of dominant follicles during the oestrous cycle of heifers Joumal of Reproduction and Fertility 83 663-671

Schams D, Schallenberger E, Gome S and Karg H (1981) Endocrine patterns associated with puberty in male and female cattle Journal of Reproduction and Fertility Supplement 30 103-110

Seidel GE, Larson LL and Foote RH (1971) Effects of age and gonadotropin treatment on superovulation in the calf Journal of Animal Science 33 617-622

Sirois J and Fortune JE (1988) Ovarian follicular dynamics during the estrous cycle in heifers monitored by real-time ultrasonography Biology of Reproduction 39 308-317

Wandji S-A, Fortier MA and Sirard M-A (1992) Differential response to gonadotropins and prostaglandin $E_{2}$ in ovarian tissue during prenatal and postnatal development in cattle Biology of Reproduction 46 1034-1041 